\title{
El conflicto del Sáhara Occidental en la prensa española: análisis del episodio Van Walsum
}

\author{
Ginés SORIANO FORTE \\ Universidad Complutense de Madrid \\ ginessoriano@gmail.com
}

Recibido: 5 de julio de 2011

Aceptado: 12 de diciembre de 2011

\begin{abstract}
Resumen
El dilatado conflicto por el territorio del antiguo Sahara Español posee un potencial informativo mucho mayor para España que para ningún otro país occidental, por su origen y por el interés social que en este país despierta. ¿La prensa española es capaz de construir una agenda informativa internacional propia para este acontecimiento exterior tan perceptiblemente cercano? Tras enunciar un polémico comentario acerca del futuro de este contencioso, el enviado especial de la ONU, Peter van Walsum, dimitió en un relevante episodio de la evolución del conflicto del Sahara Occidental. En este artículo se expone el análisis de la cobertura de este hecho, incluidos posibles sesgos ideológicos, en cuatro periódicos españoles $(A B C, E l$ Mundo, Público y en especial El País) más otro marroquí (Le Matin) como referente externo.

Palabras clave: agenda informativa internacional, conflicto, Sahara Occidental, prensa española, línea editorial

\section{The Western Sahara conflict in the Spanish press: analysis of the Van Walsum episode}

\begin{abstract}
Due to its origin and the social interest it generates, the extensive conflict over the former Spanish Sahara has a much bigger informative interest in Spain than in any other western country. Is Spanish press able to set up its own international agenda-setting about this especially close foreign news? The resignation of the UN special delegate, Peter Van Walsum, after a controversial comment about the future of this dispute has been an especially relevant moment in the Western Sahara conflict. This article is an analysis of the coverage of that episode, including possible biased information, given by four Spanish newspapers (ABC, El Mundo, Público, and specially El País) and another one from Morocco (Le Matin), as external reference.
\end{abstract}

Keywords: international agenda-setting, conflict, Western Sahara, Spanish press, publishing line

Referencia normalizada: SORIANO FORTE, Ginés (2012): "El conflicto del Sáhara Occidental en la prensa española: análisis del episodio Van Walsum“. Estudios sobre el mensaje periodístico, vol. 18, núm. 2 (julio-diciembre), págs.: 623-639. Madrid, Servicio de Publicaciones de la Universidad Complutense.

Sumario: 1. Presentación y justificación; 1.1. Objetivos; 1.2. Hipótesis. 2. Contexto; 2.1. Estudios previos; 2.2. Contexto nacional; 2.3. Contexto internacional. 3. Fuentes y metodología; 3.1. Frente al espejo de 'Le Matin' y contrastando con $A B C$, El Mundo y Público; 3.2. Periodo de estudio; 3.3. Pautas de trabajo. 4. Desarrollo; 4.1. Bases de datos y gráficos; 4.2. Análisis cuantitativo de la cobertura; 4.3. Análisis temático; 4.4. Análisis cualitativo de la cobertura; 4.5. Posibles motivos de la escasa cobertura. 5. Conclusiones; 5.1. Conclusiones generales; 5.2. Conclusiones respecto a las hipótesis planteadas. 6. Referencias bibliográficas.

\section{Presentación y justificación}

La agenda informativa internacional sigue el habitual sendero de los grandes medios y agencias occidentales (MCBRIDE et al, 1980: 79; KAPUSCINSKI, 2005: 27). Así vemos como El País o El Mundo suelen apuntar hacia lugares que Reuters o $C N N$ ya han se- 
ñalado previamente. ¿Le queda a la prensa española algún asunto cercano con el que poder configurar su propia agenda internacional?

La fallida descolonización del antiguo Sáhara Español originó un conflicto aún latente del que cabría esperar una particular atención desde España. De hecho, sigue componiendo "uno de los asuntos de política exterior que más interesa a los españoles" (CRUZ, 2008: 12), como lo muestran en este país las decenas de asociaciones de amigos de los saharauis, o la periódica acogida en familias de miles de niños originarios de los campamentos de refugiados de Tindouf (Argelia) (BÁrBUlo, 2002: 34).

De este interés nacional no escapan las administraciones locales ni regionales, como delata en Tindouf la presencia de viejos autobuses urbanos donados por Madrid, Valencia o Barcelona, y hasta de furgonetas que aún lucen sus originarios colores de la policía vasca.

\subsection{Objetivos}

Este trabajo investiga el modo en que la prensa española sigue los acontecimientos relacionados con el conflicto del Sáhara Occidental para conocer si existe una agenda informativa internacional propia en este asunto de alto interés periodístico nacional.

De no ser así, se añade como objetivo secundario a la investigación descubrir los motivos de esa desatención.

\subsection{Hipótesis}

Una dedicación insuficiente de la prensa española a este conflicto revelaría su sintonía con el tradicional desentendimiento de los sucesivos gobiernos españoles: más preocupados por sus relaciones con Marruecos que por armonizar con la sociedad española y resarcirse de su actuación tardo-colonialista (VAQUER, 2007: 125-144).

De este modo, se pretende demostrar las siguientes hipótesis:

1) La prensa española, y particularmente El País como periódico de referencia internacional, no cubre el proceso del Sáhara como corresponde a su potencial informativo en España.

2) La desatención es aún mayor en los periódicos con líneas más próximas al Gobierno central.

3) Por tanto, la prensa española no ha sabido componer su propia agenda informativa internacional en un asunto que atañe a España más que a ningún otro país occidental.

\section{Contexto}

\subsection{Estudios previos}

El conflicto del Sáhara ha sido estudiado desde las Ciencias de la Información en trabajos como las tesis doctorales de Joaquín PoRTILlo Historia de los saharauis y crónica de la agresión colonial en el Sahara Occidental (1991) y de Guadalupe PÉREZ Información y propaganda en el último período colonial español, (Ifni-Sahara, 19571976) (2005), donde se abordan periodos que concluyen en los inicios del contencioso del Sahara. 
Otros estudios, como el que da origen al artículo "España y el Sahara Occidental: la dimensión partidista" (VAQUER, 2007), exploran este asunto hasta hace pocos años, pero sin recoger la vertiente mediática.

De este modo, la presente constituiría una investigación sobre un aspecto inédito del conflicto: su reflejo en la prensa actual.

\subsection{Contexto nacional}

España, como antigua potencia colonizadora ${ }^{1}$ aún puede interpretar un papel protagonista en este contencioso, como el de Portugal en Timor Oriental en 1999 (BÁRBULO, 2002: 23; CENTENO et al, 2006: 73; TORTAJADA, 2004: 277), pero la actuación de los sucesivos gobiernos españoles no incitan a atisbar algo así (BÁRBULO, 2002: 34; CARRANCIO, 1992: 28).

En otro sentido, la existencia de centenares de asociaciones de ayuda al pueblo saharaui y el reflejo del contencioso en la prensa española se antojan fundamentales para explicar por qué Marruecos no ha conseguido aún la anexión total del territorio en disputa (BÁRBULO, 2002: 24 y 29). Como acostumbra a ocurrir en estos casos, el concurso de los medios de comunicación es capital para que no mueran las demandas independentistas saharauis (LóPEZ y SANTIAGO, 2000: 9; PrATKANIS y ARONSON, 1994: $85)$.

En España se sigue especialmente la vertiente humanitaria del problema: los miles de refugiados del interior del desierto. Dramas así suelen generar un efecto directo en la opinión pública (Colombo, 1997: 13). Si, además, la fatalidad es fruto de un conflicto, las audiencias aún son más receptivas (PizARroso et al, 2007: 41; FonTCUBERTA, 1993: 45). Con estos elementos cabría esperar una buena cobertura en los periódicos españoles.

\subsection{Contexto internacional}

Aunque es el único territorio africano con una descolonización inconclusa (MARTíNEZ, 1992: 169), apenas aparece en la exigua agenda de los medios (KAPUSCINSKI, 2005: 30), lo que Marruecos aprovecha para continuar explotando sus recursos mientras mantiene ocupado a su ejército ${ }^{2}$ alrededor de esta causa nacional (LANGE, 2007: 82). Por su parte, lo presenta como un contencioso con Argelia, tratando, sin conseguir, de difuminar el papel del Frente Polisario (Ruiz Miguel, 1995: 149-150).

Además de Marruecos, España y Argelia también están involucrados Mauritania, EE UU y Francia, y, especialmente, la organización de las Naciones Unidas:

"Por desgracia, la solución política al conflicto sigue enquistada en los pasillos de la ONU. Mientras tanto, todo un pueblo -muchos de cuyos integrantes tuvieron DNI español-sigue soportando el más terrible de los destierros en la más desolada esquina del Sáhara" (NADAL, 2004).

${ }^{1}$ El dictador Franco llegó incluso a elevar el territorio al estatus de provincia (VIDAL, 2006: 281).

${ }^{2}$ El ejército marroquí cuenta con un abultado pasado golpista (CARRANCIO, 1992: 33). 
En cuanto a los saharauis expatriados -inmersos en un limbo apátrida- conforman un tipo de desplazados abundante en otros lugares de África y al que KAPUSCINSKI se refiere como "una clase parásita de refugiados (...) que consiguen sobrevivir sólo si las ayudas siguen llegando" (KAPUSCINSKI, 2002: 110-111).

\section{Fuentes y metodología}

El objeto de este estudio es la prensa de papel, por el estatus que conserva como formato de referencia y porque su naturaleza física garantiza una concienzuda recopilación de informaciones para su posterior análisis.

Las piezas sobre el Sáhara Occidental en España son tan escasas y diversas (ayuda humanitaria, política, cultura, economía, efemérides) que resulta muy complicado extraer factores comunes con los que comparar sus coberturas. Así, se ha optado por centrar el estudio en un acontecimiento de interés para cualquier medio.

El elegido supone un momento clave de los últimos años del contencioso: la crisis que culmina en agosto de 2008 con el cese del Enviado Especial del Secretario General de la ONU en el Sáhara Occidental, Peter van Walsum.

Se ha descartado el episodio protagonizado por la activista independentista Aminetu Haidar a finales de 2009, porque extraordinariamente se recogió como un asunto nacional ${ }^{3}$, lo que lo aleja del objeto de este trabajo: sondear la existencia de una agenda de información internacional propia. En cuanto a los acontecimientos de finales de 2010 , se produjeron con este estudio ya finalizado, si bien, a falta de la correspondiente investigación, parecen corroborar las conclusiones que se exponen aquí.

El asunto analizado se inicia con la publicación en El País de una cita de Van Walsum sorprendente: "Un Sáhara independiente es inalcanzable" (CEMBrero, 2008: 2). Por primera vez en más de 30 años de conflicto un enviado especial de la ONU, principal mediador en este contencioso, afirmaba que el objetivo de una de las partes no es posible, lo que además contrasta poderosamente con la posición de la sociedad española, en la que siete de cada diez ciudadanos opinan que el Gobierno debería haber concedido la independencia al Sáhara Occidental antes de abandonar la colonia (Cruz, 2008: 12).

En total, se analizan cinco diarios (cuatro españoles y uno marroquí), pero el foco principal se dirige hacia El País, por tratarse del más internacional de los periódicos españoles ${ }^{4}$.

\subsection{Frente al espejo de 'Le Matin' y contrastando con ABC, El Mundo y Público}

Se ha optado por comparar las informaciones de El País con las del periódico marro-

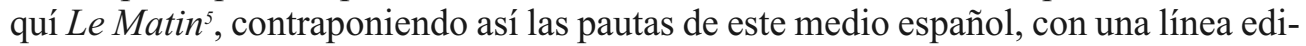

${ }^{3}$ La huelga de hambre de Haidar en Canarias criticando al Gobierno español tras su expulsión de El Aaiún movilizó a los medios españoles, que, siguiendo la estela del Ejecutivo, lo recogieron como un asunto interno.

${ }^{4}$ Es el diario generalista de pago de mayor tirada de España y el único que lleva la información internacional a sus primeras páginas.

${ }^{5}$ Le Matin du Sahara et du Maghreb, nombre completo de esta publicación editada en Casablanca, tiene una tirada de más de 80.000 ejemplares diarios (LA PARRA et al., 2007: 151). 
torial próxima al Gobierno del momento estudiado, con las que utiliza un diario del país más directamente implicado en el contencioso, Marruecos, y cuya línea editorial, a su vez, está en clara sintonía con las posiciones del régimen alauí.

Las informaciones de El País, por tanto, se ven reflejadas en Le Matin como si de un espejo se tratase: lo que aparece a la izquierda en un lado del cristal -porque el medio lo recoge con un determinado sesgo- quedará presumiblemente reflejado a la derecha en el espejo -porque el otro periódico lo lleva al lado contrario-, y lo que se sitúa en el centro -porque es poco susceptible de moverse, ideológicamente, por ejemplo- permanece igualmente en el centro al otro lado del espejo. La distinta disposición de estos reflejos en uno y otro lado, por tanto, sirven de guía para conocer como sitúa cada periódico la fisonomía del conflicto.

Por ejemplo: si los dos medios se deciden por mostrar en sus respectivas informaciones la línea oficial de la ONU -lo que quedará reflejado en el centro en ambos lados de este espejo imaginario- es posible concluir que la información ha sido tratada por ambos de una manera más ecuánime que si, pongamos por caso, uno presta más atención al Polisario y el otro al Gobierno Marroquí.

Sin embargo, no es riguroso preconcebir que contrastan lo suficiente como para obtener una comparación infalible. Para afinar más, también se utilizan de referencia los dos principales competidores españoles de El País (El Mundo y ABC) y Público, la otra cabecera española ${ }^{7}$ con una línea editorial también próxima al PSOE, partido gobernante durante el periodo estudiado.

El análisis de los cinco periódicos se complementa con una técnica eminentemente cualitativa: sendas entrevistas al periodista autor de las informaciones recogidas de $E l$ País, Ignacio CEMBRERo, y a las redactoras habitualmente encargadas del conflicto en El Mundo (Rosa MenESES) -periódico con una línea sobre el Gobierno alejada de la de El País-y Público (Trinidad Deiros), de posiciones más próximas.

\subsection{Periodo de estudio}

El periodo de estudio se ha fijado desde el 1 de agosto hasta el 18 de septiembre de 2008. Comienza una semana antes de que El País publicase las palabras del enviado especial de la ONU que acabaron por dejarle fuera del puesto ( 8 de agosto), y acaba una semana después del anuncio de que ya se había encontrado a un sustituto (10 de septiembre).

${ }^{6}$ El término alauí, se refiere a la dinastía reinante en Marruecos, no al país, como a veces se confunde. Se recoge aquí porque en el momento del estudio el Rey es el último responsable político de Marruecos (entre otras prerrogativas, preside el Consejo de Ministros, a cuyos miembros puede cesar, y puede gobernar por decreto), lo que le convierte en una figura casi análoga a la representada por el Gobierno en España. Le Matin, es el periódico cuasi-oficial de la monarquía marroquí.

${ }^{7}$ La difusión diaria en 2008 de las tres cabeceras españolas de prensa generalista de pago que más ejemplares ponían en circulación eran: El País, 2,08 millones de lectores; El Mundo, 1,3 millones y $A B C, 0,73$ millones; mientras que Público alcanzaba los 0,24 millones de lectores diarios (EGM, 2009: 6). 
En total, supone el análisis de todas las piezas informativas relacionadas con el tema de estudio, ya sea como trama principal o como cita contenida en una información de otro asunto, de 245 ejemplares de las cinco cabeceras analizadas.

En el caso de Le Matin, se han consultado los ejemplares digitalizados, publicados en su totalidad en internet (http://www.lematin.ma/Services/eMatin/dateSelect.asp).

\subsection{Pautas de trabajo}

Las piezas obtenidas se han clasificado en una base de datos confeccionada conjugando tradiciones metodológicas cuantitativas y cualitativas.

Se ha seguido principalmente la metodología propuesta por Rafael MoRENo, profesor de la Universidad Complutense de Madrid, en su asignatura del Máster en Investigación en Periodismo: discurso y comunicación llamada "Conflictos y relaciones internacionales en la información periodística". Finalmente, el procedimiento se ha adaptado a las particularidades del estudio que nos ocupa y, para facilitar el trabajo, se ha creado una plantilla de clasificación y valoración de datos que, junto a las conclusiones obtenidas, conforma una de las aportaciones de esta investigación.

Esta plantilla clasifica los datos en dos grandes bloques: Elementos de Maquetación y Elementos de Contenido.

En Elementos de Maquetación se registran la extensión de cada información, su importancia jerárquica en la página y en su sección, su fecha, posibles llamadas en portada y su ubicación dentro del periódico.

Elementos de Contenido, a su vez, se divide en dos partes: Elementos Generales de Contenido y Elementos Particulares de Contenido.

En la primera se recogen aspectos de fondo comunes a cualquier pieza, como su género, los elementos de titulación, su autor y el lugar donde se ha firmado.

En Elementos Particulares de Contenido se registran peculiaridades propias del asunto objeto del estudio y comprende tres secciones: Análisis de las Fuentes, donde se anota el ámbito de procedencia de las fuentes -entorno de la ONU, de Marruecos, de España, del Polisario, de otros países o de otro tipo- y su número; Análisis del Contenido, en el que se recogen el hilo temático que sigue cada pieza o, en su caso, si se trata de un acontecimiento aislado, el sesgo de valoración que el autor ha podido dejar en la información, y el cariz positivo o negativo de la información en su conjunto en relación a las dos partes del conflicto; y Análisis de los Protagonistas, que aunque forme parte del contenido compone un nuevo subapartado para facilitar su análisis, y donde se registra la esfera (país concreto) a la que pertenece cada categoría de actor (principal, secundario, etc.) de la noticia.

\section{Desarrollo}

\subsection{Bases de datos y gráficos}

La información recopilada se ha catalogado aplicando la plantilla propuesta (ver apartado 3.3.). La Tabla 1 muestra un fragmento de una de las tablas generadas de este modo, en este caso de El País. Se han confeccionado tablas de cada uno de los cinco periódicos estudiados. 
Tabla 1. Elementos de Maquetación en El País. Fuente: elaboración propia

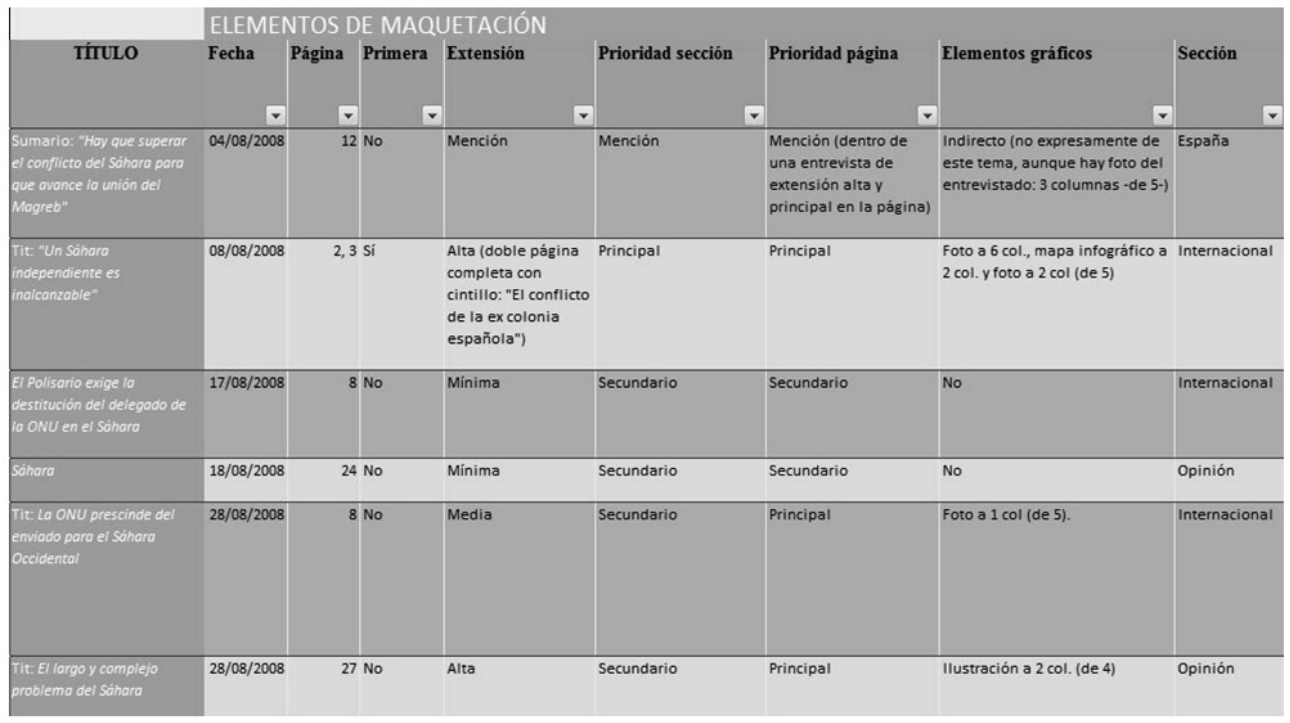

A partir de ellas se han obtenido gráficos con los que cotejar las piezas de El País con las de Le Matin y, al lado, de nuevo las de El País con las de El Mundo, Público y $A B C$. De estos gráficos (cerca de cuarenta, de los que en este artículo se exponen los más representativos) emanan los argumentos con los que se han comprobado las hipótesis propuestas para llegar a unas conclusiones válidas. Dichos argumentos están plasmados en los apartados que siguen a continuación.

\subsection{Análisis cuantitativo de la cobertura}

La dedicación cuantitativa de Le Matin al conflicto es muy superior a la de El País (Gráfico 1), aún cuando el periódico español publica más días (un 14\%) que el marroquí, que no sale los sábados.

Gráfico 1. Número de piezas en cada periódico sobre el Conflicto del Sahara Occidental por semana. Fuente: elaboración propia
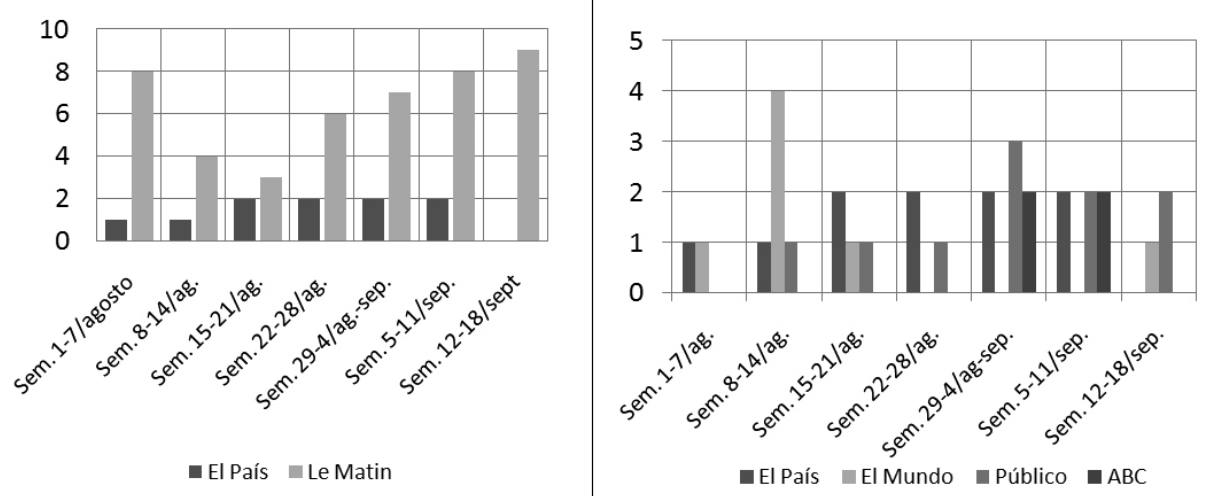
Es razonable que el primero se preocupe de un asunto que le es más propio, pero no es natural que el diario español atienda tan pobremente un conflicto originariamente protagonizado por España y que sigue interesando a su sociedad. Los demás diarios estudiados comparten esta escasa atención.

\subsection{Análisis temático}

Las escasas menos de 1,5 piezas semanales que El País dedica al asunto estudiado se centran casi todas (el 80\%) en la polémica sobre Van Walsun (Gráfico 2), quizá el episodio más relevante de este conflicto ${ }^{8}$ desde que James Baker dimitiera del mismo cargo en 2004.

En los demás diarios españoles todavía se recoge menos. $A B C$, que es el que más informa sobre ello, dedica apenas el $25 \%$ de sus piezas sobre el Sáhara a este tema.

Gráfico 2. Temática de las informaciones (en porcentaje del total para cada cabecera).

Fuente: elaboración propia

\begin{tabular}{|c|c|c|c|c|c|}
\hline & El País & Le Matin & El Mundo & Público & $\mathrm{ABC}$ \\
\hline Sobre Van Walsum & $80 \%$ & $26,7 \%$ & $0 \%$ & $10 \%$ & $25 \%$ \\
\hline Proceso del Sáhara en general & $10 \%$ & $6,7 \%$ & $14,3 \%$ & $30 \%$ & $0 \%$ \\
\hline Visita de Rice a Marruecos & $10 \%$ & $8,9 \%$ & $0 \%$ & $10 \%$ & $50 \%$ \\
\hline Encuentro Sec. Gral. ONU-Zapatero & $0 \%$ & $0 \%$ & $0 \%$ & $10 \%$ & $25 \%$ \\
\hline Relaciones España-Marruecos & $0 \%$ & $0 \%$ & $57,1 \%$ & $0 \%$ & $0 \%$ \\
\hline Apoyos directos a Marruecos & $0 \%$ & $17,8 \%$ & $0 \%$ & $0 \%$ & $0 \%$ \\
\hline Contra el Polisario o Argelia & $0 \%$ & $8,9 \%$ & $0 \%$ & $0 \%$ & $0 \%$ \\
\hline Efemérides & $0 \%$ & $11,1 \%$ & $14,3 \%$ & $0 \%$ & $0 \%$ \\
\hline Otros & $0 \%$ & $19,9 \%$ & $14,3 \%$ & $40 \%$ & $0 \%$ \\
\hline
\end{tabular}

Cabe señalar que el episodio Van Walsum se inicia con unas declaraciones recogidas por El País, y que el posterior anuncio de abandono del cargo también es una exclusiva de este periódico, como confirma $A B C$ (2008: 30) y Le Matin (2008: 3), por lo que su interés aún podría haber sido menor si no hubiese tenido una participación tan trascendental en los acontecimientos.

8 Ignacio Cembrero reconoce en la entrevista realizada en junio de 2009 por el autor para esta investigación que, en su periódico, El País y sobre el Sáhara Occidental: "Pocos temas han ocupado más de un día. En 2005 lo ocupó la revuelta de los saharauis en algunas ciudades. En 2008 las declaraciones de Van Walsum sobre la negociación en Manhasset, su dimisión/destitución y el nombramiento de un sustituto". 


\subsection{Análisis cualitativo de la cobertura}

Aquí El País supera a Le Matin, aunque sin alcanzar una calidad suficiente. Las fuentes, por ejemplo, son muy escasas (Gráfico 3): sólo una en más del $70 \%$ de sus piezas, lo que imposibilita un mínimo contraste de las informaciones.

Esta carencia la trata de suplir con lo que hemos clasificado como "documentación", que consiste en emplear como fuente algo ya publicado, quebrantando de nuevo la calidad.

El recurso a la "documentación" es todavía más abundante en El Mundo y Público. Las periodistas que cubren habitualmente el conflicto para estos dos medios citan 9 una variedad de fuentes distintas que aseguran consultar en sus informaciones, pero ninguna de las piezas analizadas ha sido escrita por estas autoras, lo que evidencia aún más la despreocupada atención al Sahara de estas dos cabeceras.

En $A B C$ sí se perciben al menos dos fuentes en la mitad de sus piezas, lo que, sin embargo, sigue resultando escaso.

Gráfico 3. Número de fuentes empleadas en cada información (en porcentaje del total para cada cabecera, sin incluir editoriales y opinión) Fuente: elaboración propia

\begin{tabular}{|l|l|l|l|l|l|}
\hline & El País & Le Matin & El Mundo & Público & $A B C$ \\
\hline 3 fuentes & $0,0 \%$ & $3,0 \%$ & $0,0 \%$ & $0,0 \%$ & $0,0 \%$ \\
\hline 2 fuentes & $14,3 \%$ & $9,0 \%$ & $0,0 \%$ & $0,0 \%$ & $50,0 \%$ \\
\hline 1 fuente & $71,4 \%$ & $63,6 \%$ & $20,0 \%$ & $33,3 \%$ & $25,0 \%$ \\
\hline Sin especificar & $14,3 \%$ & $9,0 \%$ & $0,0 \%$ & $0,0 \%$ & $0,0 \%$ \\
\hline Ninguna fuente & $0,0 \%$ & $15,2 \%$ & $80,0 \%$ & $66,7 \%$ & $25,0 \%$ \\
\hline
\end{tabular}

También supera El País a Le Matin empleando la firma personal ${ }^{10}$ en todas sus informaciones -algo casi inédito en Le Matin-; al consagrar a un mismo periodista a estos asuntos, y al identificar en qué lugares se redactan las piezas, lo que nunca señala Le Matin. Igualmente destaca en estos tres aspectos sobre los demás periódicos españoles analizados, a lo que contribuye su concentración en Van Walsum.

Asimismo El País despunta en la extensión de sus informaciones, que es alta en un tercio de sus piezas, según el baremo ponderado en cada cabecera adoptado en esta investigación. Mientras en Le Matin sólo alcanza esta categoría el 17\% (Grafico 4). Además, el 10\% de las informaciones de El País son piezas principales en su sección y un $40 \%$ lo son dentro de la página, por sólo el $4,4 \%$ y el $15,5 \%$ respectivamente de las que recoge el periódico magrebí. El 30\% también incluye un despliegue gráfico mediano o grande, cuando únicamente algo más del 15\% de las informaciones de Le Matin tiene este tratamiento.

${ }^{9}$ Entrevistas realizadas a Rosa Meneses (El Mundo) y Trinidad Deiros (Público) en junio de 2009 para esta investigación.

10 "El hombre que pone su nombre en un texto se siente responsable de lo que escribió" (KAPUSCINSKI, 2005: 14). 
Los demás periódicos españoles, en general, quedan aquí igualmente detrás de $E l$ País. Casi una de cada nueve piezas de El Mundo y la mitad de las de Público tratan el conflicto como simple mención contenida en otras informaciones, y los dos cuentan con un despliegue gráfico que no ilustra ni el $25 \%$ de sus informaciones, mientras que en El País se alcanza el $40 \%$.

$A B C$ dedica un espacio estimable a sus piezas, pero sin alcanzar a El País. Su despliegue gráfico también es notable: el $75 \%$ de sus informaciones contiene alguna imagen, de tamaño medio en todos los casos.

El País vuelve a evidenciar así unos índices de calidad más altos, de los que, sin embargo, no se deduce una mayor preocupación por el Sahara Occidental: parece limitarse a rentabilizar sus primicias sobre Van Walsum, única vertiente de la que se ocupa.

Gráfico 4. Número de informaciones según su extensión (porcentaje del total para cada cabecera). Fuente: elaboración propia
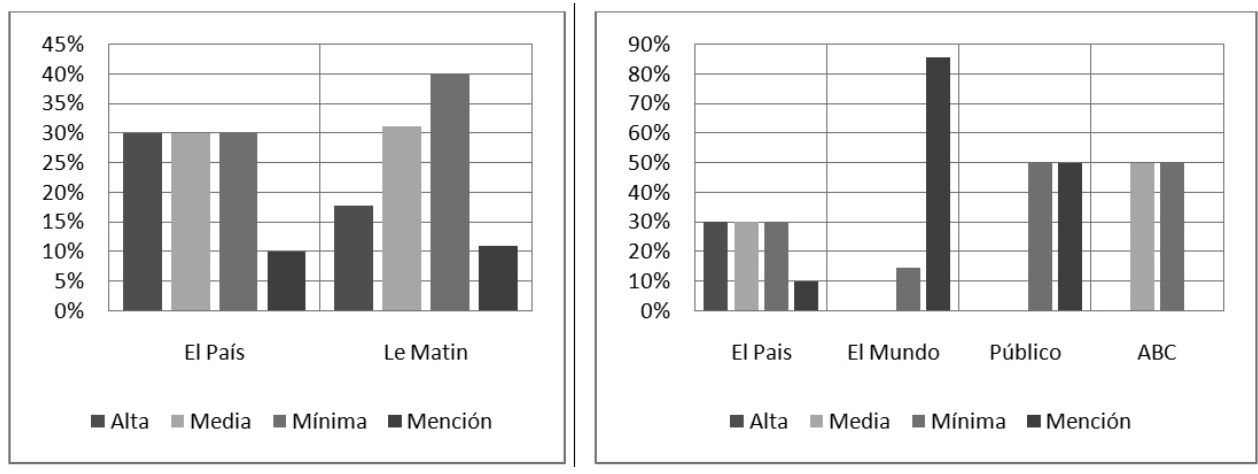

Su apatía también se revela en el esfuerzo por ceñir el conflicto a la sección de internacional (Gráfico 5), pese a sus, en ocasiones, implicaciones nacionales. Dos circunstancias muestran claramente este intento. La primera es la escasa relevancia de la única mención al Sáhara Occidental en su sección de nacional durante el tiempo de estudio: una escueta pregunta sobre el conflicto en una entrevista al Secretario de Estado de Asuntos Exteriores de España, Ángel Lossada.

La segunda es más notable: El País no recoge ni la reunión en España del presidente del Gobierno, José Luis Rodríguez Zapatero, y el Secretario General de la ONU, Ban Ki-moon, en la que debaten el proceso del Sáhara, lo que sí cubren $A B C$ y Público -extrañamente tampoco lo hace El Mundo-, ni tampoco la reacción del portavoz del Partido Popular en la Comisión de Asuntos Exteriores, Gustavo de Arístegui, acerca de acontecimientos relacionados directamente con las polémicas declaraciones de Van Walsum. Esta última noticia fue difundida a principios de agosto por la agencia española Servimedia, pero ninguno de los periódicos españoles estudiados la divulga en sus páginas. Sí, lo hace, en cambio, Le Matin, que incluso dedica un editorial a la postura del PP.

El Mundo y $A B C$ tienen más en cuenta las implicaciones españolas y circunscriben a nacional más informaciones (casi el $60 \%$ el primero y el $25 \%$ el segundo). Público sigue la pauta de El País y la única pieza que envuelve en nacional sólo es una mención de la citada reunión de Zapatero y Ban Ki-moon. 
Entre tanto, Le Matin se esfuerza por no sacar el asunto de su ámbito nacional aunque el protagonista de la información sea otro país, como ocurre en ocasiones. Además, más de la cuarta parte de sus piezas son editoriales ${ }^{11}$, por sólo una de cada diez de El País.

El rotativo marroquí, por tanto, parece tan preocupado por aleccionar sobre el asunto como el periódico español por apenas tocarlo -o hacerlo de la manera más ajena: la sección de internacional-. En cambio El Mundo sí opta por mencionarlo en algún editorial donde recuerda, por ejemplo, "acontecimientos históricos aún próximos, como la Marcha Verde, por la que España perdió el Sáhara” (El Mundo, 2008: 3).

Gráfico 5. Secciones de las informaciones (en porcentaje del total para cada cabecera).

Fuente: elaboración propia

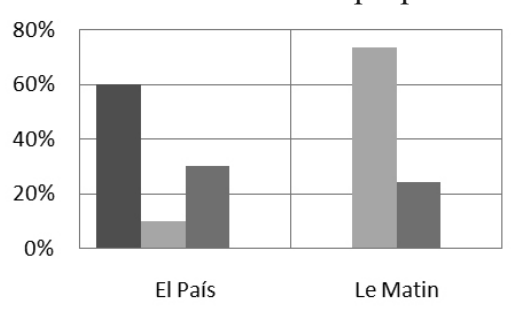

- Internacional nacional apinión aCultura

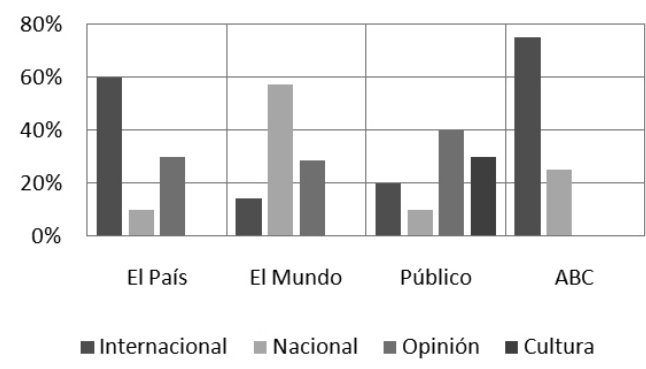

En cuanto a la evolución del conflicto, contrasta el sesgo positivo del rotativo norteafricano en la mitad de las informaciones con la interpretación negativa que plasma el autor de las de El País en el $80 \%$ de sus piezas ${ }^{12}$ (Gráfico 6).

El Mundo también deja un rastro negativo en más del $70 \%$ de sus informaciones, y $A B C$ en la mitad. Público es el único de los españoles que muestra algún sesgo positivo, aunque únicamente en informaciones culturales.

Gráfico 6. Claves temáticas de las informaciones (en porcentaje del total para cada cabecera). Fuente: elaboración propia
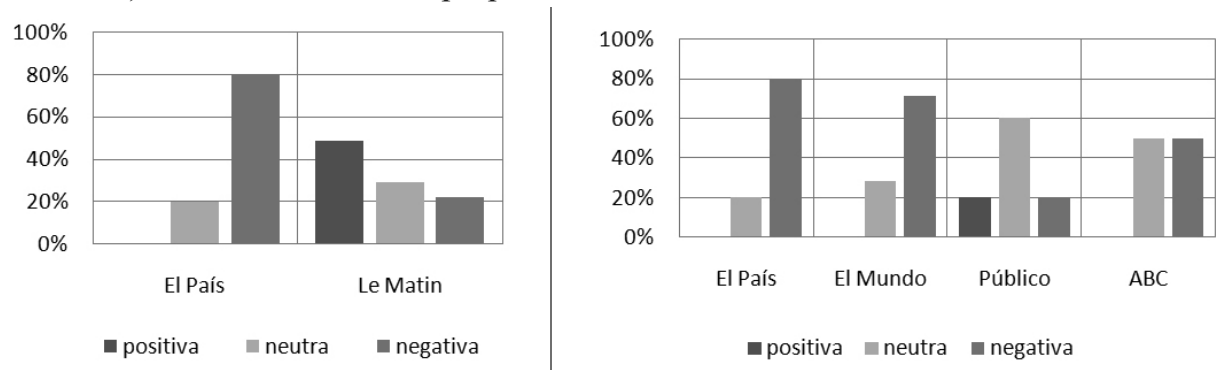

${ }^{11}$ Conviene recordar que los medios de comunicación marroquíes son especialmente sensibles a este conflicto (VERMEREN, 2002: 308).

12 De ello es plenamente consciente el periodista que las ha escrito, Ignacio CEMBRERo, y así lo reconoce en la entrevista realizada en junio de 2009 por el autor para esta investigación. 
Por otra parte, atendiendo al fondo de las informaciones, se observa que más de tres cuartas partes de las piezas de Le Matin tratan algún asunto esencialmente positivo para Marruecos.

El País es mucho más equilibrado: un $30 \%$ de sus informaciones son positivas para Marruecos, un 40\% para el Polisario, que se beneficia de la destitución de Van Walsum, tema estrella del periódico, y en el 30\% restante no se puede determinar.

El Mundo presenta informaciones positivas principalmente para Marruecos, a quien considera el más beneficiado en este conflicto. Público se muestra más positivo con el Polisario en la mitad de sus piezas, pero son referencias a meros actos culturales. Y $A B C$ de nuevo es el más equilibrado imprimiendo un cariz neutral en todas sus piezas.

En cuanto a los protagonistas principales El País señala casi en exclusiva a Van Walsum, de la ONU (Gráfico 7), que resulta más relevante que las propias partes en disputa.

En cambio, Le Matin sólo le sitúa como protagonista principal en el 20\% de sus informaciones, mientras en el 50\% este estatus lo ocupan actores de la propia esfera de Marruecos, especialmente el propio Rey, o de otros países que figuran apoyando sus reivindicaciones.

Gráfico 7. Esfera del protagonista principal de cada información (en porcentaje del total para cada cabecera). Fuente: elaboración propia

\begin{tabular}{|l|l|l|r|r|r|}
\hline & El País & Le Matin & El Mundo & Público & ABC \\
\hline Saharauis & $0,0 \%$ & $8,9 \%$ & $14,3 \%$ & $30,0 \%$ & $0,0 \%$ \\
\hline Argelo-polisario & $0,0 \%$ & $17,9 \%$ & $0,0 \%$ & $0,0 \%$ & $0,0 \%$ \\
\hline Marruecos & $0,0 \%$ & $24,5 \%$ & $42,9 \%$ & $0,0 \%$ & $0,0 \%$ \\
\hline España & $10,0 \%$ & $4,4 \%$ & $42,9 \%$ & $20,0 \%$ & $25,0 \%$ \\
\hline ONU & $80,0 \%$ & $20,0 \%$ & $0,0 \%$ & $10,0 \%$ & $25,0 \%$ \\
\hline EE UU & $10,0 \%$ & $0,0 \%$ & $0,0 \%$ & $0,0 \%$ & $50,0 \%$ \\
\hline Otros países & $0,0 \%$ & $24,5 \%$ & $0,0 \%$ & $20,0 \%$ & $0,0 \%$ \\
\hline
\end{tabular}

En contraste, El Mundo confiere a España la mayor importancia a la vez que destaca a los principales actores del conflicto (Marruecos, que figura como el mayor responsable, y el Polisario). Argelia, recibe igualmente más atención que en El País, y la ONU, en cambio, apenas obtiene relumbre en El Mundo.

Lo más destacable en Público es la gran presencia del Polisario, pero aquí también son menciones en piezas de carácter cultural, y algún artículo de opinión.

En $A B C$ sí destaca la ONU, pero superada entre los protagonistas principales por EE UU, debido a su mayor cobertura de un viaje de la Secretaria de Estado norteamericana a Marruecos. Igualmente, como El País, guarda una cierta simetría en la aparición de los dos actores principales del conflicto, Marruecos y el Polisario, si bien 
$A B C$ les otorga un mayor protagonismo. España también destaca aquí muy por encima del lugar que ocupa en las informaciones de El País.

$A B C$ es el más equilibrado en las esferas de los actores de sus informaciones. Aparecen todas las importantes.

\subsection{Posibles motivos de la escasa cobertura}

Si bien los conflictos atraen público (PIZARRoso et al, 2007: 41), la inacción espanta a los medios. Los tres periodistas consultados de El País, El Mundo y Público coinciden en señalar al aletargamiento del contencioso del Sahara como principal causa del desinterés mediático; una explicación que no es del todo satisfactoria para el episodio en el que se centra esta investigación: uno de los más relevantes del conflicto en muchos años.

Por el contrario, aquí se percibe la influencia de los propios medios en la evolución del conflicto, ya que "fijan el orden de prioridad de los acontecimientos y establecen cuáles son los temas de actualidad y cuáles no, con lo que determinan la capacidad de discriminación temática del público" (LÓPEZ Y SANTIAGO, 2000: 9).

En este punto, la colaboración de un medio tan relevante como El País resultaría especialmente útil para un Ejecutivo que ha abandonado sus simpatías hacia el independentismo saharaui en beneficio de una potente campaña de acercamiento a Marruecos (VAQUER, 2007: 125-144), dejando incluso a un lado sus primigenios empeños por solucionar el conflicto ${ }^{13}$. Abunda así en el tradicional divorcio con la postura de la sociedad civil:

"Paradójicamente, a medida que han ido accediendo al Gobierno, los gabinetes de Adolfo Suárez, Felipe González y, en menor medida, José María Aznar han cerrado los ojos ante la represión marroquí contra los saharauis. Por el contrario, la opinión pública ha multiplicado sus acciones de ayuda" (BÁRBULO, 2002: 34).

Si el Gobierno no quiere incomodar a Marruecos (VAQUER, 2007: 125-144), El País, tradicionalmente próximo al partido del Gobierno durante el periodo analizado ${ }^{14}$, tampoco querrá incomodar al Gobierno, y su concurso es muy valioso, ya que con su escasa atención al drama saharaui estaría impidiendo lo que Furio CoLOMBO define como:

"Un efecto inmediato no sólo sobre las conciencias sino también sobre los acontecimientos y sobre los intereses internos de otros países, a causa de la red de relaciones tejidas o intentadas por Naciones Unidas, que sitúan a las opiniones públicas y a los gobiernos locales frente a problemas que afectan a la vida interna de una comunidad lejana" (CoLOMBO, 1997: 13)

13 El Gobierno socialista llegó al poder en 2004 con la promesa de acabar en seis meses con este conflicto, lo que además revela que en la clase política española aún se identifica el asunto saharaui como parte de la política nacional (VAQUER, 2007: 125-144), contrastando con el tratamiento rigurosamente internacional con que El País lo cubre.

14 "El contenido de los medios no sólo depende de los intereses del público y de los propios medios: es también el resultado de los intereses de distintos sectores de la sociedad, que pretenden dar a conocer al público determinados hechos y opiniones a través de los medios de comunicación", o no darlos a conocer, se podría añadir (FONTCUBERTA, 1993: 54). 
Conviene recordar aquí que, como señala el profesor Rafael MoRENo (2008: 122), "una vez que los medios interrumpen la evolución de un conflicto deben ser conscientes de que también asumen una responsabilidad no sólo con sus lectores sino también en su globalidad".

\section{Conclusiones}

\subsection{Conclusiones generales}

"Desde sus orígenes el periodismo se ha visto amenazado y asediado por cuatro adversarios: la escasez de fuentes, la fuerza del poder, el riesgo de la censura y el estado de ánimo de la opinión pública" (CоLOMBo, 1997: 9). Según lo visto, en las informaciones analizadas de El País acerca del conflicto del Sáhara Occidental se ha sucumbido a algunas de estas amenazas. En ellas hay "escasez de fuentes"; se deja sentir "la fuerza del poder" del Gobierno español, y "el estado de ánimo de la opinión pública" lleva camino de perder interés por un conflicto carente hoy día de espectacularidad ${ }^{15}$. Hablar de un "riesgo de la censura" se antoja en cambio demasiado aventurado a la luz de los datos recabados. Pero no está de más tener en cuenta que:

"Ya no existe la censura como tal, con excepción de ciertos países; en su lugar se utilizan otros mecanismos -que definen qué destacar, qué omitir, qué cambiar-para manipular de manera más sutil" (KAPUSCINSKI, 2005: 14).

En todo caso, la información publicada por El País sobre el Sáhara Occidental es muy escasa y, aunque supere a los demás, no alcanza la calidad suficiente, lo que puede influir en la evolución del propio proceso privando de una información suficiente a una opinión pública inicialmente interesada.

El Mundo y $A B C$ tampoco dedican un amplio despliegue a este asunto, pero sí muestran una mayor implicación de España en el conflicto, sobre todo el primero. $A B C$ recuerda incluso que el Gobierno no ha cumplido su promesa de que el contencioso internacional se resolvería durante sus primeros meses de mandato.

$A B C$ es el más equilibrado: recoge todos los asuntos importantes del conflicto y a todos sus protagonistas, e incluso consulta más fuentes que los demás. La única tacha es el reducido número de sus piezas informativas.

El Mundo, por su lado, dedica un despliegue mayor y se compromete más con el conflicto vislumbrando la responsabilidad de Marruecos en su enquistamiento.

En cambio Público, al igual que El País, huye de cualquier consideración interna de España en este problema. Se centra en vertientes culturales y humanitarias y no informa sobre el asunto Van Walsum. Y aún va más lejos: si El País constriñe sus informaciones a la sección de internacional, Público las aleja de cualquier compromiso relegándolas a la sección de cultura.

\subsection{Conclusiones respecto a las hipótesis planteadas}

De todo lo anterior es posible confirmar las hipótesis planteadas en la siguiente medida:

15 "Por verdadera que sea una información, carecerá de valor si no está en condiciones de interesar a un público que, por otro lado, es crecientemente caprichoso" (KAPUSCINSKI, 2005: 24). 
1) Se confirma que los periódicos españoles no siguen el proceso del Sáhara Occidental en un grado que se corresponda con las circunstancias del conflicto: ni se ajustan al protagonismo de España en el conflicto ni a la atención de la sociedad española sobre uno de los asuntos internacionales que más le interesan. El País, en particular, sí hace notar su condición de periódico español de referencia internacional, pero sus informaciones resultan escasas y con lagunas.

2) Mientras los diarios más críticos con el Gobierno del PSOE (El Mundo y ABC) muestran algunas aristas de un conflicto que al Ejecutivo no le interesa que se vean, los diarios más cercanos al mismo (El País y Público) parecen cuidarse de no alimentar el esencial "apoyo de la opinión pública española al Frente Polisario" (BÁRBULO, 2002: 29). En este punto se encuentran las lagunas de El País que se aluden en el punto anterior.

3) Derivado de la conclusión 1) se confirma que la prensa española, en general, no ha sabido confeccionar una agenda de información internacional propia en lo concerniente al conflicto del Sáhara Occidental: resulta demasiado irregular, pues recoge unos acontecimientos mientras se deja otros de considerable importancia. El País sí ha sabido, no obstante, colocarse como timonel en un episodio de gran relevancia en el que ha servido de guía para otros medios. Sin embargo, ha olvidado otros asuntos importantes, lo que evidencia una mayor preocupación por sacar rédito a su propio scoop ${ }^{16}$ que por mantener una buena información sobre el Sáhara Occidental.

\section{Referencias bibliográficas}

ABC (2008): "La ONU no renueva a Van Walsum como enviado especial para el Sahara", en $A B C, 29$ de agosto, sección Internacional (p. 30).

BÁRBULO, Tomás (2002): La historia prohibida del Sáhara Español. Barcelona. Ediciones Destino.

CARRANCIO, Magdalena (1992): El Sahara Occidental: ifin del colonialismo en África?, Rosario (Argentina), Centro de Estudios en Relaciones Internacionales de Rosario.

CEMBRERO, Ignacio (2008): “Un Sáhara independiente es inalcanzable”, en El País, 8 de agosto, sección Internacional (p. 2).

CENTENO, Rui; PROENÇA, Francisco; NOVAIS, Rui, y BACELAR DE VASCONCELOS, Pedro (2006): Timor-Leste da Nação ao Estado. Oporto. Edições Afrontamento.

COLOMBO, Furio (1997): Últimas noticias sobre el periodismo. Barcelona. Editorial Anagrama.

CRUZ, Marisa (2008): "Los españoles no se fían del vecino del sur", en El Mundo, 13 de agosto, sección España (p.12).

${ }^{16}$ Como se ha explicado, los acontecimientos del periodo estudiado -episodio Van Walsumse originan a partir de la publicación de unas declaraciones en El País, entre otras primicias de este diario sobre este asunto. 
EGM, (2009): "Ranking de Medios Impresos", en Resumen general EGM: febrero a noviembre de 2009: http://www.aimc.es/aimc.php?izq=egm.swf\&pag_html=si $\&$ op $=$ cuatro $\&$ dch=02egm/24.html. [fecha de consulta:3 de febrero de 2010]

FONTCUBERTA, Mar (1993): La noticia. Barcelona. Paidós.

GUERRA GÓMEZ, Amparo (2005): De emisarios a protagonistas. Boceto para una historia del periodismo corresponsal. Madrid, Fragua.

KAPUSCINSKI, Ryszard (2002): Los cínicos no sirven para este oficio. Barcelona, Anagrama.

KAPUSCINSKI, Ryszard (2005): Los cinco sentidos del periodista: estar, ver, oír, compartir, pensar. México, D.F. Fundación Nuevo Periodismo Iberoamericano.

LE MATIN (2008): "Peter van Walsum critique la société civile espagnole", en Le Matin, 9-10 de agosto de 2008, sección Nation (p. 3).

LA PARRA, Daniel; PENALVA, Clemente; y MATEO, Miguel (2007). "La política árabe y mediterránea de España. La imagen de España y Marruecos en la prensa marroquí y española durante el incidente del islote de Perejil (Leyla)", en Revista Cidob d'Afers Internacionals: http://dialnet.unirioja.es/servlet/articulo?codigo= 3109732\&orden $=231675 \&$ info $=$ link. [fecha de consulta: 6 de febrero de 2010]

MCBRIDE, Sean, y otros (1980): Un solo mundo, voces múltiples. México, Fondo de Cultura Económica.

MORENO IZQUIERDO, Rafael (2008): "Las responsabilidades inevitables de los periodistas en conflictos armados". Cuadernos de periodistas, $\mathrm{n}^{\circ} 13$. Madrid, Asociación de la Prensa de Madrid, pp. 113-122.

NADAL, Paco (2004): "El pueblo sin tierra", en VV. AA.: Saharauis. Solo el desierto. Madrid, Rivas-Sahel.

PÉREZ, Guadalupe (2005): Información y propaganda en el último período colonial español, (Ifni-Sahara, 1957-1976). Tesis doctoral dirigida por Alejandro García Pizarroso. Facultad de Ciencias de la Información. Universidad Complutense de Madrid.

PIZARROSO QUINTERO, Alejandro; GONZÁLEZ, Marta; y SAPAG, Pablo (2007): Periodismo de guerra. Madrid, Síntesis.

PORTILLO, Joaquín (1991): Historia de los saharauis y crónica de la agresión colonial en el Sahara Occidental. Tesis doctoral dirigida por Antonio Sánchez-Bravo. Facultad de Ciencias de la Información. Universidad Complutense de Madrid.

PRATKANIS, Anthony y ARONSON, Elliot (1994): La era de la propaganda. Uso y abuso de la persuasión. Barcelona, Paidós Comunicación (edición original de 1992).

ROJO LÓPEZ, Alfonso (1995): Reportero de guerra. Barcelona, Planeta.

RUIZ MIGUEL, Carlos (1995): El Sahara Occidental y España: Historia, Política y Derecho. Análisis crítico de la política exterior española. Madrid, Dykinson. 
SAHAGÚN, Felipe (2004): "Corresponsales de guerra: de la paloma a internet". Cuadernos de periodistas, $\mathrm{n}^{\circ}$ 0. Madrid, Asociación de la Prensa de Madrid, pp. 33-44. TORTAJADA, Ana (2004): Hijas de la arena. Barcelona, Lumen.

VAQUER, Jordi (2007). "España y el Sahara Occidental: la dimensión partidista”, en Revista Cidob d'Afers Internacionals: http://dialnet.unirioja.es/servlet/articulo?codigo $=3109730 \&$ orden $=231676 \&$ info=link $[$ fecha de consulta: 6 de febrero de 2010]

VERMEREN, Pierre (2002): Marruecos en transición. Granada, Almed.

VIDAL, Lorenzo M. (2006): Ifni, la prensa y la guerra que nunca existió. Madrid, Almena Ediciones. 